Original Research

\title{
Post-process optimization of 3D printed poly(lactic-co-glycolic acid) dental implant scaffold for enhanced structure and mechanical properties: effects of sonication duration and power
}

\author{
R. N. V. C. Virinthorn ${ }^{1} \cdot$ M. Chandrasekaran ${ }^{2} \cdot$ K. Wang ${ }^{3} \cdot$ K. L. Goh $\mathbb{1}^{1,2}$
}

Received: 13 April 2020 / Accepted: 13 July 2021 / Published online: 31 July 2021

(c) The Author(s) 2021

\begin{abstract}
We described a technique of a post-process stage to partially remove the poly(vinyl alcohol) (PVA) binder in Poly(lactic-coglycolic acid) (PLGA) dental scaffolds. The scaffolds were exposed to ultrasonic waves while immersed in an ethanol/ acetone solvent mixture that possessed both polar and nonpolar properties. A factorial experiment was conducted in which the scaffolds were treated to three levels of sonication power $\left(p_{\mathrm{W}}\right): 0,20 \%(22 \mathrm{~W})$ and $40 \%(44 \mathrm{~W})$, and soaking duration $(t)$ : 5,15 , and $30 \mathrm{~min}$. The treated scaffolds were characterized by FT-IR, optical microscopy, and mechanical (compressive) testing. FT-IR revealed that the amount of PVA decreased with increasing $p_{\mathrm{W}}$ and $t$. Two-way ANOVA revealed that increasing $p_{\mathrm{W}}$ and $t$, respectively, resulted in increasing scaffold surface area to volume (SVR). Sonication and solvent caused structural damage (i.e., unevenness) on the scaffold surface, but the damage was minimal at $20 \% p_{\mathrm{W}}$ and $30 \mathrm{~min}$. The optimal values of $p_{\mathrm{W}}$ and $t$ resulting in enhanced fracture strength, strain and toughness were $20 \%$ and 30 min, respectively, which corroborated the findings of minimal structural damage. However, sonication had no significant effects on the scaffold stiffness. Mechanistic analysis of the effects of sonication predicted that the ultrasonic energy absorbed by the scaffold was sufficient to disrupt the van Der Waals bonds between the PVA and PLGA but not high enough to disrupt the covalent bonds within the PLGA. This technique is promising as it can partially remove the PVA from the scaffold, and mitigate problematic issues down the line, such as thermal degradation during sterilization, and undue delay/variability in biodegradation.
\end{abstract}

Supplementary information The online version contains supplementary material available at https://doi.org/10.1007/s10856021-06561-3.

K. L. Goh

kheng-lim.goh@ncl.ac.uk

1 Newcastle University in Singapore, SIT@NYP, 172A Ang Mo Kio Avenue 8 \#05-01, Singapore 567739, Singapore
2 Newcastle Research \& Innovation Institute Singapore, 80 Jurong East Street 21, \#05-04, Singapore 609607, Singapore

3 Emirate Nuclear Technology Center (ENTC), Department of Chemical Engineering, Khalifa University of Science and Technology, Abu Dhabi, United Arab Emirates PO Box 2533 


\section{Graphical Abstract}

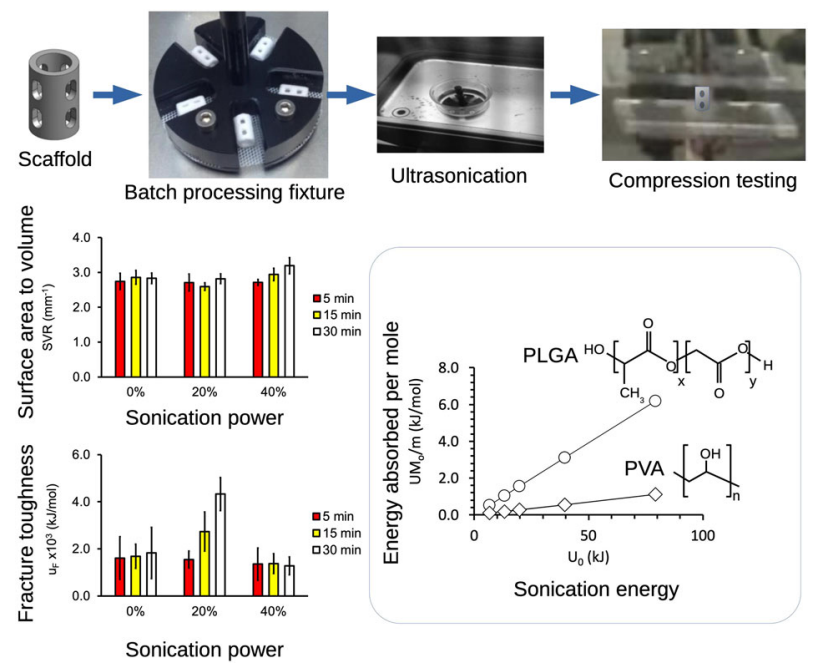

\section{Introduction}

Preserving the natural contour of the alveolar ridge after a tooth extraction process, known as dental socket preservation, is important as it can facilitate future reconstruction with an implant prothesis. This can be achieved by inserting fillers, such as grafts or synthetic scaffolds, into the toothextracted site to prevent the alveolar ridge from collapsing [1], thus retaining the natural contour of the alveolar ridge as well as minimizing bone lost by bone resorption [2]. Of late, porous and moldable synthetic scaffolds made from poly lactic-co-glycolic acid (PLGA) [3-6] are popular alternatives to dental bone grafts [7] for dental socket preservation. As an implant, PLGA-based scaffolds are biocompatible with the human body [3-6]. Its biodegradation rate and mechanical properties can also be tailored by varying the ratio of its copolymers, namely lactic acid and glycolic acid, which are bonded together via ester linkages $[4,5,8]$. For dental application, one advantage of using such a synthetic implant is that the scaffold in the socket could be flushed to the level of the base of the bone $[3,4]$.

In powder-based additive manufacturing processes, such as selective laser sintering and inkjet printing, the forming of polymer-based scaffolds would require a binder for binding the powders [9]. With regard to the manufacturing of the PLGA scaffolds by inkjet printing, Poly(vinyl alcohol) (PVA) has been identified as a binder for the PLGA powders [8, 10-12]. It acts as a surfactant to emulsify, stabilize the dispersed state of PLGA and, consequently, maintain the scaffold structural integrity during the processing stage. Binding the PLGA powders in this way can result in a structure that possesses the resultant strength and stiffness of the scaffold which are compatible to those of alveolar bone [7]. Different methods of forming PLGA scaffolds using PVA as a binder have been reported, such as melt-molding particulate leaching to produce sponge scaffold [8], wet spinning to produce hollow (porous-wall) fiber scaffold [10] and emulsion electrospinning to produce nanofibrous mat-like scaffolds [12]. For details of previous studies related to the current paper, see Table SI-1 in Supplementary Information for a summary of the findings of the mechanical properties and structure of PLGA-based scaffold that utilized PVA as a binder.

The use of PVA as a binder for facilitating the forming of the porous PLGA scaffold presents several problematic issues for the scaffolds. First, during dry heat sterilization (whereby the temperature could go up to $160^{\circ} \mathrm{C}$ or higher) [13, 14], a proportion of the PVA could thermally degraded to produce polyene (yellowish) residues, resulting in decolorization of the scaffold [15-18]. While this is esthetically unacceptable from the dental perspective, the thermally degraded PVA exhibits lower fracture strength and strain [19]. Consequently the lower fracture strength and strain could reduce the overall structural integrity of the scaffold, as well as increase the variability in the final mechanical property. This presents a hurdle to achieve the desired mechanical properties of the scaffold. The second issue is related to biodegradability. Ideally, the scaffold should provide an adequate duration for the alveolar bone to regenerate as the scaffold biodegrades. Although the PLGA scaffold is suited for this purpose, the PVA present in the scaffold may have lower degradation rate and this could result in undue delay in degradation. The extent to which the PVA degrades depends on the degree of hydrolysis involved in the production of the PVA [8]. In addition, the PVA residuals formed an interconnected network with the PLGA and this could hinder the degradation of the PLGA [11]. The rate of 
diffusion of the surrounding body fluids into the PLGA could decrease and, consequently, this decreases the speed of degradation and further pose a mismatch between the scaffold degradation rate and bone tissue regeneration rate. Again, this presents a challenge to meeting regulatory requirements for the product to state the biodegradation time.

Ideally, one may wish to implement a post-processing stage that can cause the PVA to leach or to be removed by a solvent, while the PLGA remains inert to the solvent or else possesses a low dissolution rate in the solvent. One might wish to optimize the PVA concentration through such a postprocess approach to achieve a scaffold with the desired mechanical property with minimal disruption to the overall structure.

From the current understanding of the use of shock waves generated by cavitation (during sonication) for breaking down powders into nanoparticles [20], we proposed a novel approach to use ultrasonic waves to dislodge as much PVA residuals as possible in the PLGA-based scaffold, in the presence of a solvent mixture (possessing both polar and nonpolar properties). The main purpose of the polar-nonpolar solvent mixture was to facilitate the dissolution and rebonding of PLGA particles within the scaffold so as to minimize the diminution of the structural integrity of the final PLGA scaffold. However, the sonication and chemical effects on the structure and mechanical properties of the PLGA scaffold are not clearly understood. Here, we investigated the effects of sonication power, $p_{\mathrm{W}}$, and soaking duration, $t$, on the mechanical properties and structure of the PLGA/PVA scaffolds and the optimal levels for the $p_{\mathrm{W}}$ and $t$ for the PLGA scaffolds to achieve enhanced mechanical properties.

\section{Materials and method}

\subsection{Theory}

As ultrasonic waves produced by the ultrasonic machine propagate through the ethanol/acetone medium containing the PLGA scaffolds, this would generate cyclical high and low pressures throughout the medium [20]. At low pressures (rarefaction), microscopic vapor bubbles (cavitation) were formed; at high pressures (compression), the bubbles collapsed and produced shock waves of high energy, in the form of microscopic jet stream, traveling at high velocity, with pressure of the order of hundreds of mega pascals and temperatures higher than the $T_{\text {bath }}$. The total amount of energy, $U_{0}$, generated by an ultrasonic machine is related to the $p_{\mathrm{W}}$ and $t$, according to

$U_{0}=p_{\mathrm{W}} t$

[20]. This energy is capable of dispersing nanometer size particles. According to this relationship, two PLGA/PVA scaffolds treated at a given $\mathrm{p}_{\mathrm{W}}$, for two different ts, could lead to different degree of removal of PVA. Similarly, two PLGA/PVA scaffolds treated at a given $t$, for two different $p_{\mathrm{W}} \mathrm{s}$ could also lead to different degree of removal of PVA. Now, the $U$ would be partially attenuated (the energy would be dissipated into the solvent mixture) as the ultrasonic wave propagated through the solvent mixture toward the scaffold. Consider an ultrasonic source generating an acoustic intensity of $I_{0}\left(\mathrm{~W} / \mathrm{m}^{2}\right)$, at a given distance (x) from the source. The acoustic intensity, $I$, is given by

$I=I_{0} \exp (-2 \alpha \mathrm{x})$

where the absorption coefficient

$\alpha \sim \mathrm{G} \mu \mathrm{f}^{2} / \gamma$

$\mu$ represents the dynamic viscosity $\left(\mathrm{kg} \mathrm{m}^{-1} \mathrm{~s}^{-1}\right), \gamma$ is the density of the solvent mixture, and $\mathrm{G}$ is a constant [20]. The nature of $\mathrm{G}$ may be understood by noting that both $\mathrm{G}$ and $\mu$, when combined as $G \mu$, can be identified as the effective dynamic viscosity where $G$ serves as a weighting factor to modulate $\mu$. According to Taurozzi et al. they have assigned $G=2 / 3$. This is not based on a detailed analysis of the viscosity of the liquid but — with a numerical value less than unity-it indicates that the weighting factor provides the lower limit of $\mu$.

As the waves collapse, how this result in breaking the PLGA powders would depend on the sonication energy [20]. At low energy, this could disperse the powder agglomerates which were bound by van Der Waals forces; at higher energy this could break up the individual particles, which were bound by chemical bonds [20]. Here, Eqs. (1), (2), (3) provide the means to estimate this effect.

\subsection{PLGA scaffolds}

Figure 1A shows schematics of a PLGA/PVA scaffold. The design specifications required that the dimensions of the scaffold were as follows: outer diameter $\left(D_{\mathrm{OD}}\right)=3.6 \mathrm{~mm}$; inner diameter $\left(D_{\mathrm{ID}}\right)=2.0 \mathrm{~mm}$; length of the scaffold $\left(L_{0}\right)=$ $6.5 \mathrm{~mm}$. The 3D printed PLGA/PVA scaffolds were purchased from M/s Bio-scaffold International Pte Ltd (BSI, Singapore). These were patented PLGA-based dental scaffolds, known otherwise as Bioscaff Alvelac [7]. According to BSI, the PLGA was purchased from Corbion (PURAC, www. corbion.com). The PLGA possessed a monomer ratio of lactic acid to glycolic acid of 85:15. The PVA was purchased from Merck Pte. Ltd. (affiliate of Merck KGaA, Darmstadt, Germany, www.merckmillipore.com).

BSI used a Z-Corp 310 Plus 3D printer (www. 3dsystems.com, previously under Z-Corp, Burlington, USA) to print the scaffolds. This printer had a main features 


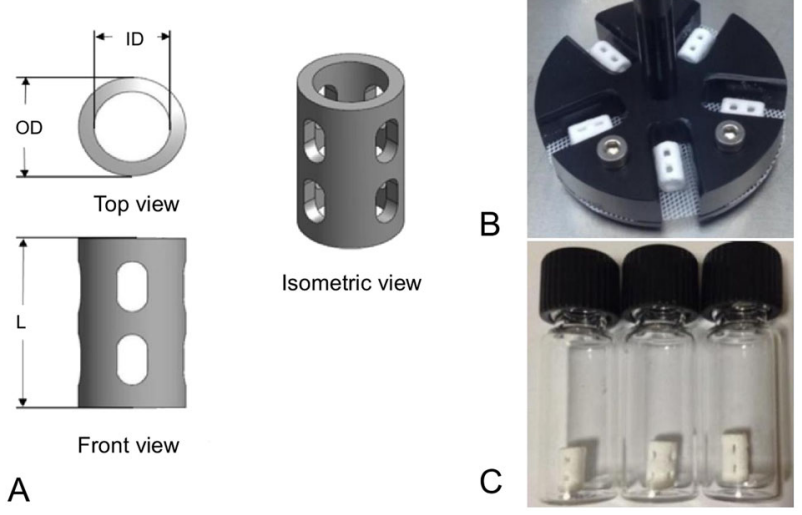

Fig. 1 PLGA/PVA scaffolds. A Schematics of a scaffold showing the top, isometric and side view. The outer diameter $\left(D_{\mathrm{OD}}\right)$, inner diameter $\left(D_{\mathrm{ID}}\right)$, length $\left(L_{0}\right)$, and total surface area $\left(A_{\mathrm{s}}\right)$ of the printed scaffold were $3.6 \mathrm{~mm}, 2.0 \mathrm{~mm}, 6.5 \mathrm{~mm}$ and $126.0 \mathrm{~mm}^{2}$, respectively. B Scaffolds held in a customized jig used for agitation during sonication. C Scaffolds after sonication

resolution of $300 \times 450 \mathrm{dpi}$ and vertical-build speed of $1.0 \mathrm{inch} / \mathrm{h}(25 \mathrm{~mm} / \mathrm{h})$. While the printer could accommodate a maximum build size of $8 \times 10 \times 8$ inches $(203 \times 254 \times$ $203 \mathrm{~mm}$ ), the size of each PLGA scaffold to be produced was much smaller than the maximum size capacity. Thus it was possible to produce multiple scaffolds $(<80)$ in a single run with a duration of about $20 \mathrm{~min}$ per run.

Details of the exact formulation of the blended mixture of PLGA and PVA that led to the final product, i.e., the scaffold, were proprietary information of the PLGA scaffold manufacturing company and were not made available to us. We have been informed by the company that the scaffolds were made from blending milled PLGA and PVA followed by 3D printing. According to information gathered from a published patent document [7], PLGA granules were milled at a frequency of about 30 cycles to yield a particle sizes below $300 \mu \mathrm{m}$ and suitable sizes were selected for printing the scaffold. The PLGA scaffold manufacturing company had informed the authors that the volume ratio of PVA:PLGA ranged 2:8-7:10, and they could not be more specific given that the exact composition of the PVA and PLGA was proprietary information. We have attempted to provide an estimate of the composition of the components of the PLGAbased scaffold for informational purpose. The starting point of our calculation was based on the volume ratio information provided by the PLGA scaffold manufacturing company, informed by the basic design concepts of composite materials and foams from the patent document [7]. For the benefit of the reader, in Section 2 of Supplementary Information, we have provided the details of our approach to arrive at simple orderof-magnitude estimates of the composition of the PLGA-based scaffold. We reported that the volume fractions of PVA and PLGA used were 0.4 and 0.6 , respectively, valid to order of magnitude. This yielded a volume ratio of $2: 3$ which falls within the range of values of the volume ratio provided by the manufacturer.

\subsection{Post-processing by sonication}

The acetone ( $>99.5 \%$ purity) and ethanol ( $\sim 95 \%$ purity) were purchased from Sigma Aldrich (www.sigmaaldrich. com). Both acetone and ethanol (which contain polar and nonpolar groups) were mixed to produce a solvent for the scaffold post-processing study, for the purpose of dissolving polar (e.g., water, PVA) and other nonpolar molecules. The method for the preparation of the polarnonpolar solvent mixture was proprietary information. In short, a starting amount (also proprietary information) of the respective components of the acetone/ethanol solvent was developed first, following by varying the amount of the ethanol, to establish the range of $p_{\mathrm{W}}$ and $t$ to be used in the current study. This led to a feasible scaffold with reduced amount of PVA present, adequate mechanical properties and adequate surface to volume ratio. Importantly, this was done by selecting values of $p_{\mathrm{W}}$ and $t$ within the extremes of practical values, though some limitations were placed on the values of $p_{\mathrm{W}}$ to ensure that the scaffold experienced moderate depolymerization of PVA [21], as explained in Section 2.1.

Careful consideration of the choice of the values of $\mathrm{p}_{\mathrm{W}}$ would be required in order to moderate the disruption of the PVA network and dislodge the PVA from the PLGA, with minimal effect on depolymerization and disruption to the bulk of the PLGA. It has been reported that an input power of $10 \mathrm{~W}$ could result in depolymerization of PVA to a small extent (about 10\%) [21]. At a higher input power, namely $200 \mathrm{~W}$ (i.e., the upper limit of their study), the PVA in solution experienced extensive depolymerization [21]. Thus, there exists a threshold power related to the formation of cavitation (i.e., the cavitation threshold) below which depolymerization of PVA in solution will not occur. Unfortunately, the precise cavitation threshold is still not known. Thus, in this study, the values of $\mathrm{p}_{\mathrm{W}}$, namely $20 \%(22 \mathrm{~W})$ and $40 \%(44 \mathrm{~W})$ were chosen as these represented the intermediate values of the two extremes (10 W and $200 \mathrm{~W})$.

The ultrasonic machine (Elma Transonic T $490 \mathrm{DH}$ ) used in this study had the following specifications: ultrasonic frequency of $40 \mathrm{kHz}$, total power consumption of $330 \mathrm{~W}$, and $p_{\mathrm{W}}$ (RMS) of $110 \mathrm{~W}$ (at 100\%) and $130 \mathrm{~W}$ (at 140\%). The tank internal dimensions were $240 \mathrm{~mm} \times 137 \mathrm{~mm} \times$ $100 \mathrm{~mm}$. During sonication, the scaffolds (in the beaker) were placed at the center of the tank.

A factorial experiment was conducted in which the scaffolds were treated to three levels of $p_{\mathrm{W}}$ namely 0 (i.e., no sonication), $20 \%(22 \mathrm{~W}), 40 \%(44 \mathrm{~W})$, and three levels of $t$, namely 5,15 , and $30 \mathrm{~min}$. This yielded a series of 
experimental runs that corresponded to different combinations of $p_{\mathrm{W}}$ and $t$ using Eq. (1), by setting values of $p_{\mathrm{W}}=$ $22 \mathrm{~W}$ (i.e., $20 \%$ ) and $44 \mathrm{~W}$ (i.e., $40 \%$ ) at the respective $t$ levels, namely 5,15 , and $30 \mathrm{~min}$.

For the factorial experiment the PLGA/PVA scaffold specimens were grouped according to the respective combinatorial levels of the $p_{\mathrm{W}}$ and $t$. Five specimens were used for each combination of levels of treatment. A solvent mixture containing $100 \mathrm{ml}$ of ethanol and acetone (the exact amount was proprietary information) was prepared in a beaker and magnetically stirred at $250 \mathrm{rpm}$ for $15 \mathrm{~min}$. The specimens were held in a customized jig which could accommodate 5 scaffolds at a time (Fig. 1B) and the jig was introduced into the beaker (containing the solvent mixture). Sonication began after the beaker was placed in a water bath in the ultra-sonication machine. Thereafter, the scaffolds were removed from the solvent and a simple mechanical process was applied to extract water and ethanol/acetone droplets that were present in the scaffolds by gently pressing and pin-rolling the scaffolds on a flat Teflon mesh. Water and ethanol/acetone were the key components necessary for PVA binding with PLGA during the $3 \mathrm{D}$ printing process. However, the presence of water and ethanol/acetone in the PLGA (entrapped in closed pores) after forming could produce the following results: (1) the generation of residual pressure within closed pores; (2) incomplete bonding of PLGA particles; (3) unintended degradation during the sterilization step. Removing the excess water and ethanol/acetone droplets was a key step following the forming stage. Figure $1 \mathrm{C}$ shows a photo of the scaffolds at the end of the post process.

\subsection{Scaffold dimensions}

After the sonication treatment, prior to mechanical testing, the $D_{\mathrm{OD}}, D_{\mathrm{ID}}$, and $L_{0}$ of the scaffold were measured using a conventional optical microscope (Olympus BX51M model). In addition to the measurement of scaffold dimensions, microscopic examinations of the scaffold surfaces were also performed using the optical microscope.

Measurements were carried out at four sites along the scaffold axis to account for non-uniformity. With regard to the $D_{\mathrm{ID}}$, measurements were carried out at the two end faces of the scaffold. To ensure consistency in the measurements of the $D_{\mathrm{OD}}$ and $L_{0}$, the scaffold was placed horizontally on a $\mathrm{V}$ shape groove jig, mounted on the microscope stage. To measure $D_{\mathrm{ID}}$, each specimen was vertically positioned on a microscopic slide. With regard to $L_{0}$, measurements were carried out at four sites around the scaffold. The measured values were averaged to obtain representative values of $D_{\mathrm{OD}}, D_{\mathrm{ID}}$, and $L_{0}$, respectively. The cross-sectional area (A) of the specimen was estimated by setting $A=\pi\left[D_{\mathrm{OD}}^{2}-D_{\mathrm{ID}}^{2}\right] / 4$.
The $A$ and $L_{0}$ were used in the computation of the stress and strain from the force-displacement data obtained from compressive testing (Section 2.6).

In addition, the ratio of surface area to volume (SVR) of the scaffold was determined as follows. The surface area of the scaffold $\left(A_{\mathrm{S}}\right)$ was estimated by summing the areas of the outer and inner surfaces and the $A$ at the two end faces. The volume of the scaffold was estimated by $A L_{0}$. Thus the SVR was estimated to order of magnitude by $A_{S} / A L_{0}$.

\subsection{Fourier Transform Infrared (FT-IR) spectroscopy}

Fourier transform infrared (FT-IR) spectroscopic analysis of the composition of the PLGA-based scaffold was carried out on the pieces of crushed scaffolds. FT-IR was performed using a Brucker Vertex $80 \mathrm{v}$ spectrometer with a parallel beam transmittance accessory. Using the on-board camera of the spectrometer, surfaces with a high degree of evenness were located through the display screen to ensure optimal interaction of the IR radiation with the specimen. Then each transmittance spectrum was recorded from 1000 to $3000 \mathrm{~cm}^{-1}$ using the following input settings: pressure $250 \mathrm{~Pa}$, resolution of $4 \mathrm{~cm}^{-1}$ and 500 scans per specimen.

\subsection{Mechanical tests}

Compression tests were carried out on a mechanical tester (Shimazu AGS-X). A 10-kN loadcell was used to measure the force generated in the specimen while it was subjected to compressive loading. The scaffolds were compressed in the direction perpendicular to the circular face of the cylindrical samples at a rate of $5 \mathrm{~mm} / \mathrm{min}$ until the scaffold was crushed.

Stress-strain data was derived from the forcedisplacement data of each specimen. Figure 2 shows a graph of typical stress versus strain curves corresponding to PLGA/PVA scaffolds treated at three different $p_{\mathrm{W}}$ values. Stress was calculated using $\sigma=F / A$, where $F$ represented the force generated in the specimen during compression, and $A$ the original cross-sectional area of the scaffold that was in contact with the platens of the mechanical tester. Strain was calculated using $\varepsilon=\Delta / L_{0}$, where $\Delta$ represented the displacement during compression.

The compressive fracture strength $\left(\sigma_{\mathrm{U}}\right)$, strain at fracture $\left(\varepsilon_{\mathrm{U}}\right)$, stiffness $(E)$, and fracture toughness $\left(u_{\mathrm{F}}\right)$ were determined for each specimen. The $\sigma_{U}$ was associated with the maximum stress of the stress-strain curve; the corresponding strain point parameterized the $\varepsilon_{\mathrm{U}}$. The $\mathrm{E}$ was determined from the gradient of the linear region of the stress-strain curve, which was located in between point $\mathrm{c}$ and $\mathrm{d}$, where the external load was predominantly resisted by the bulk material. The $u_{\mathrm{F}}$ was determined from the area under the stress-strain curve from the origin to $\varepsilon_{\mathrm{U}}$. 


\subsection{Statistical analysis}

Statistical analysis was carried out to evaluate the effects of the $p_{\mathrm{W}}$ and $t$ on the scaffold structure and mechanical properties using software (RStudio, Version 1.2.5033). Following checks to ensure that the data satisfied the conditions of homogeneity of variance of the residuals and normality of residuals, a one and two-way (two-tailed) analysis of variance was used to evaluate our results at an

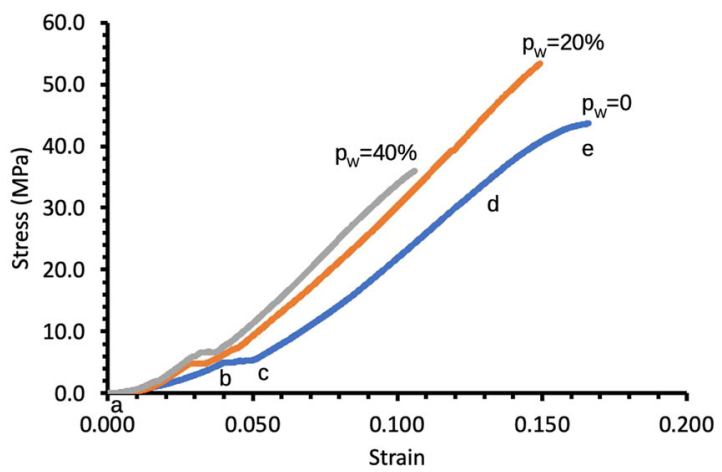

Fig. 2 Stress-strain curves of the PLGA/PVA scaffolds were derived from compression testing. These were obtained for $p_{\mathrm{W}}=0,20$, and $40 \%$ at $t=30 \mathrm{~min}$. The region between points a to $\mathrm{b}$ indicates the region of initial loading. The region between points $\mathrm{b}$ to $\mathrm{c}$ indicates a characteristic plateau, suggesting possible collapse of the engineered holes in the scaffold (Fig. 1A). The region between points $\mathrm{c}$ to $\mathrm{d}$ accounts for the mechanical support provided by the PLGA-based material to resist the load. Point e indicates the point of fracture alpha level of 0.05 . A total of 45 scaffolds were tested and used for the statistical analysis. The number of test specimens for each treatment was 5 . Results were expressed as mean \pm standard deviation $(\mathrm{SD})$.

\section{Results}

\subsection{Microscopic examination}

As obtained PLGA scaffolds showed a characteristic white surface (Fig. 1C). Treating the specimens to soaking durations of 5,15 , and $30 \mathrm{~min}$, at the respective sonication power (i.e., $p_{\mathrm{W}}=0,20$, and $40 \%$ ), did not result in appreciable changes in the color texture.

When sonication was applied to the scaffolds at 5, 15, and $30 \mathrm{~min}$, optical microscopy revealed large areas of irregular patches as seen in Fig. 3. Depending on the $p_{\mathrm{W}}$ level, scaffolds could appear as partially darkened, i.e., some regions of the surface appeared darker than others; other scaffolds appeared completely darkened. These were attributed to unevenness of the surface, following dislodging of PVA, and/or dissolution and re-bonding. Figure SI-1 in the Supplementary Information section provides additional examples (macroscopic and microscopic views) to illustrate the unevenness. Thus the uneven scaffold surface could be observed as a result of the following effects: (1) parallel light rays incident onto
Fig. 3 Optical micrographs of PLGA/PVA scaffold treated to the respective sonication power levels, $0,20\left(p_{\mathrm{W}}\right)$, and $40 \%$ $\left(p_{\mathrm{W}}\right)$, at 5,15 , and $30 \mathrm{~min}$ soaking duration. Here, each panel (a to i) shows the surface of a PLGA specimen, corresponding to a specific treatment level. For instance, the image in panel a was derived from a specimen treated at $p_{\mathrm{W}}=$ $0 \%$ and $t=5 \mathrm{~min}$. Scale bar indicates $100 \mu \mathrm{m}$

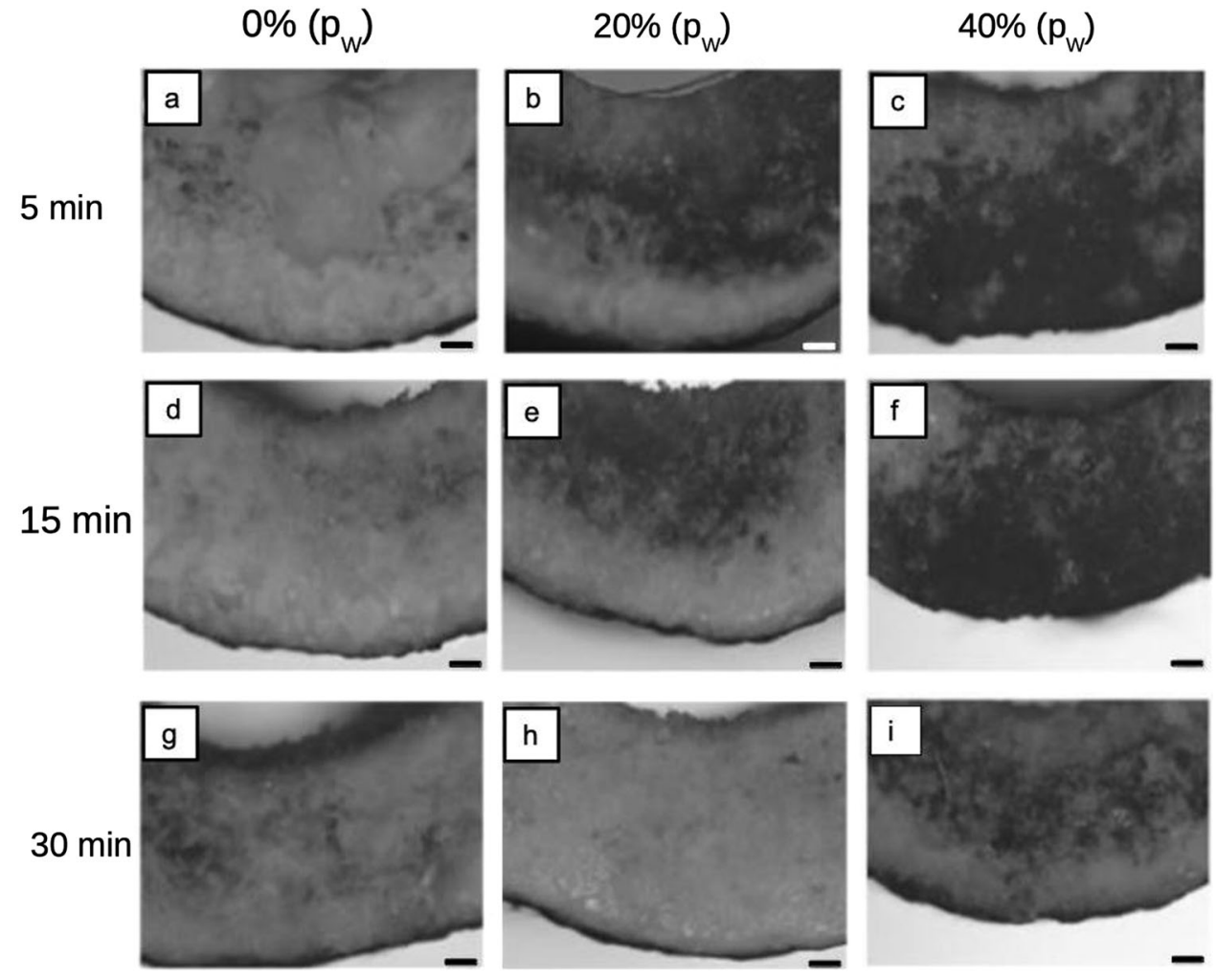


the scaffold surface were scattered randomly leading to diffuse reflection; (2) limitation in the depth of field so that extended undulated layers arising from particle $(300 \mu \mathrm{m})$ re-bonding were located beyond the depth of field. On that note, the scaffolds least affected were those treated to $p_{\mathrm{W}}=20 \%$ and $t=30 \mathrm{~min}$.

\subsection{Fourier transform infrared (FT-IR) spectroscopy}

To evaluate the extent of the PVA present in the PLGAbased scaffold, the FT-IR spectra were analyzed for changes in the intensity of the absorption bands of the PLGA-based scaffold that could be attributed to the changes in the respective PLGA and PVA.

Figure 4 shows typical FT-IR spectra of PLGA/PVA scaffolds corresponding to $p_{\mathrm{W}}=0,20$, and $40 \%$ at $t=5 \mathrm{~min}$. The wavenumbers labeled on the graphs corresponded to

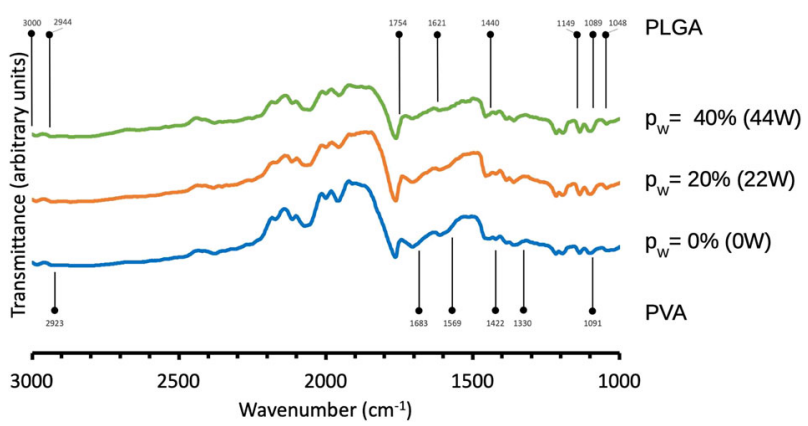

Fig. 4 Fourier transform infrared spectra of PLGA/PVA scaffold treated to the respective sonication power levels, $0,20\left(p_{\mathrm{W}}\right)$, and $40 \%$ $\left(p_{\mathrm{W}}\right)$, at 5 min soaking duration. Of note, PVA and PLGA have linear formula given by $\left(\mathrm{CH}_{2} \mathrm{CH}(\mathrm{OH})\right)_{\mathrm{n}}$ and $\left(\mathrm{C}_{3} \mathrm{H}_{4} \mathrm{O}_{2}\right)_{\mathrm{x}}\left(\mathrm{C}_{2} \mathrm{H}_{2} \mathrm{O}_{2}\right)_{\mathrm{y}}$ respectively "mid-point" value of range of wavenumbers reported in the literature for the respective PLGA and PVA material. The key absorption bands of the PVA overlapped those of the PLGA in the high wavenumber region $\left(3000-2923 \mathrm{~cm}^{-1}\right)$, mid-range region $\left(1754-1330 \mathrm{~cm}^{-1}\right)$, and low wavenumber region $\left(1149-1048 \mathrm{~cm}^{-1}\right)$. Separately, we have identified three regions of interest that revealed reductions in the PVA content in the PLGA-based scaffold. The first region corresponded to the wavenumbers between 1740 and $1569 \mathrm{~cm}^{-1}$. It showed that the intensity of the bands decreased appreciably with increase in $p_{\mathrm{W}}$. These decrease were attributed to the diminishing population of the $\mathrm{C}=\mathrm{O}$ and $\mathrm{C}-\mathrm{O}$ (stretching mode) from the acetate group of the PVA (in the presence of the poly (vinyl acetate) (PVAc), owing to possible incomplete hydrolysis in the polymerization process to obtain PVA, resulting in a mixture of PVA/PVAc [22]). The second region corresponded to the wavenumbers between 1422 and $1330 \mathrm{~cm}^{-1}$; it showed that the intensity of the bands decreased (albeit slightly) with increase in $p_{\mathrm{W}}$. These reduction in intensity were attributed to the diminishing population of the $\mathrm{C}-\mathrm{H}$ (bending vibration of $\mathrm{CH}_{2}$ and deformation vibration) from the PVA. The third region corresponded to the wavenumbers between 1149 and $1048 \mathrm{~cm}^{-1}$. In this region, at $p_{\mathrm{W}}=0$, the vibration bands arising from $\mathrm{C}-\mathrm{O}$ stretching (PVA) were masked by those of $\mathrm{C}-\mathrm{O}-\mathrm{C}, \mathrm{C}-\mathrm{O}$, and $\mathrm{C}-\mathrm{CH}_{3}$. As the $\mathrm{p}_{\mathrm{W}}$ increased, this resulted in an overall narrowing of the band due to the reduction in population of $\mathrm{C}-\mathrm{O}$ from the PVA. Concomitantly, the effect from the $\mathrm{C}-\mathrm{O}-\mathrm{C}, \mathrm{C}-\mathrm{O}$, and $\mathrm{C}-\mathrm{CH}_{3}$ (PLGA) became more dominant and thus the bands appeared more pronounced at higher $p_{\mathrm{W}}$. Table 1 provides further details about these absorption bands.

More importantly, as the absorption bands at 1433 , 1330, and $1091 \mathrm{~cm}^{-1}$ corresponding to PVA were still
Table 1 Summary of band frequencies corresponding to PVA and PLGA, derived from FT-IR of PLGA/PVA scaffold

\begin{tabular}{llll}
\hline Polymer & Wavenumber $^{\mathrm{a}} \mathrm{cm}^{-1}$ & Chemical bonds & References \\
\hline PLGA & $3000-2996(2998)$ & $\mathrm{CH}_{2}$ asymmetric stretching & {$[27-29]$} \\
& $2962-2922(2943)$ & $\mathrm{CH}_{2}$ asymmetric stretching & {$[12,27-29]$} \\
PLGA & $1759-1747(1742)$ & $\mathrm{C}=\mathrm{O}$ stretching & {$[12,27-32]$} \\
PLGA & 1620 & $\mathrm{C}-\mathrm{O}$ & {$[28]$} \\
PLGA & $1454-1421(1438)$ & $\mathrm{C}-\mathrm{H}$ stretching & {$[12,28,29,31,32]$} \\
PLGA & $1392-1363(1377)$ & $\mathrm{O}-\mathrm{H}$ bending & {$[27-29,32]$} \\
PLGA & $1182-1113(1147)$ & $\mathrm{C}-\mathrm{O}-\mathrm{C}$ stretching, C-O stretching & {$[12,27-29,32,33]$} \\
PLGA & $1093-1082(1087)$ & $\mathrm{C}-\mathrm{O}$ stretching vibration from ether group & {$[28,29,32]$} \\
PLGA & $1047-1046(\sim 1046)$ & $\mathrm{C}-\mathrm{CH}$ 3 & {$[29,32]$} \\
PVA & $2924-2917(2921)$ & $\mathrm{C}-\mathrm{H}$ stretching & {$[34,35]$} \\
PVA & $1714-1650(1682)$ & $\mathrm{C}=\mathrm{O}$ and C-O stretching from acetate groups & {$[34-36]$} \\
PVA & 1568 & $\mathrm{C}=\mathrm{O}$ stretching from acetate groups & {$[37]$} \\
PVA & $1425-1418(1422)$ & $\mathrm{C}-\mathrm{H}$ bending vibration of $\mathrm{CH}_{2}$ & {$[34,37]$} \\
PVA & $1334-1324(1329)$ & $\mathrm{C}-\mathrm{H}$ deformation vibration & {$[34,37]$} \\
PVA & $1099-1081(1090)$ & $\mathrm{C}-\mathrm{O}$ stretching of acetyl groups & {$[34-38]$} \\
\hline
\end{tabular}

${ }^{a}$ Figure in parenthesis denotes the mid-point value of the range of wavenumbers 


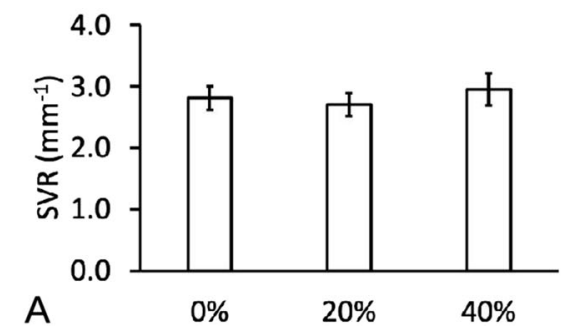

Fig. 5 Main effects plots of the surface area to volume ratio (SVR) of PLGA/PVA scaffold with respect to (A) sonication power, $p_{\mathrm{W}}$, and (B) soaking duration, $t$. Note that the value of the respective bars on each

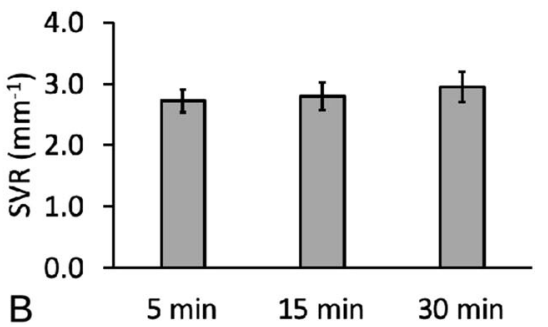

graph represented the average (plus-minus standard deviation of sample) of all the levels at each $p_{\mathrm{W}}$ or at each $t$
Fig. 6 Interaction plots of the surface area to volume ratio (SVR) of PLGA/PVA scaffold with respect to (A) sonication power, $p_{\mathrm{W}}$, and $(\mathbf{B})$ soaking duration, $t$
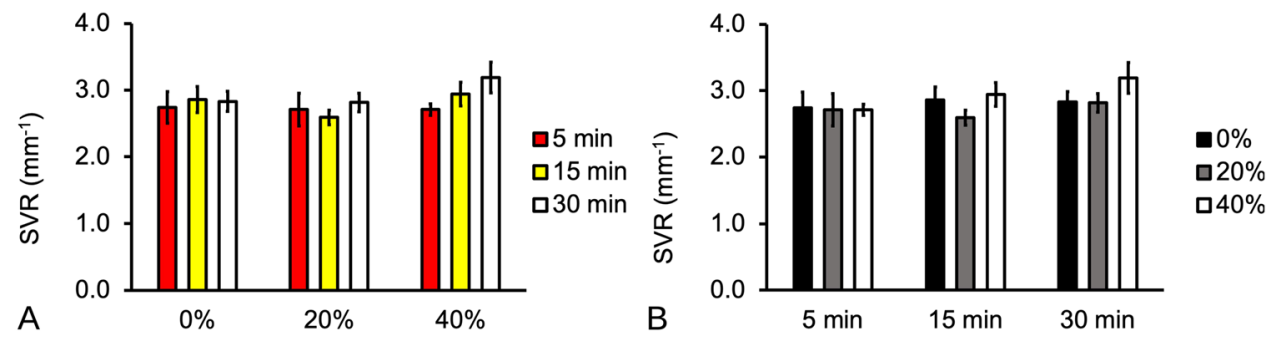

visible at $p_{\mathrm{W}}=20$ and $40 \%$, this suggested that the PVA was still presence in the scaffold, albeit in reduced amount. In Section 4 of the Supplementary Information, we presented a description of our approach to apply models based on the classic Beer-Lambert law, to compute order of magnitude estimates of the volume fraction of PVA residue present in the sonicated scaffold. Recalled that the volume fraction of PVA present in the pristine scaffold was estimated at 0.4 (Section 2.2). We predicted that, to order of magnitude, the volume fraction of PVA decreased to (i) $0.31\left(p_{\mathrm{W}}=20 \%\right)$ and (ii) $0.26\left(p_{\mathrm{W}}=\right.$ $40 \%$ ). Thus the amount of PVA residue present in the sonicated scaffold was $0.78\left(p_{\mathrm{W}}=20 \%\right)$ and $0.66\left(p_{\mathrm{W}}=\right.$ $40 \%$ ) times smaller than that of the pristine scaffold. Overall, this indicated a progressive decrease in PVA with increasing $p_{\mathrm{W}}$.

\subsection{Scaffold surface area to volume ratio}

Two-way ANOVA showed that the $P$ values for $\mathrm{p}_{\mathrm{W}}$ $(P=0.003)$ and $t(P=0.005)$ were both very small, indicating that there was very strong evidence that both factors affected SVR. The $P$ value for the interaction $(P=0.053)$ was greater than the alpha level, showing that there was no evidence for an interaction between the factors. The main effects may be interpreted independently of one another: sonication power affects SVR as does only soaking duration.

The overall effects may be summarized by the main effects plot for $p_{\mathrm{W}}$ and $t$ (Fig. 5) which showed that increases in sonication power and soaking duration resulted in increases in SVR. For completeness, the details of the variation of SVR with respect to $t$ at each level of $p_{W}$ and vice versa are shown in the interaction plots (Fig. 6). Thus, the main effects plots of SVR versus $p_{\mathrm{W}}$ showed that at lower sonication power, i.e., $p_{\mathrm{W}}=20 \%$, changes in $t$ did not lead to an appreciable change to the SVR (Fig. 6A). At higher sonication power, i.e., $p_{\mathrm{W}}=40 \%$, the SVR increased with increasing $t$ (Fig. 5A). Similar trends were also observed for the case of SVR versus $t$ (Fig. 5B and Fig. 6B). Overall, these results indicated that the scaffold volume could be drastically reduced compared to the surface area. The results of the SVR are summarized in Table 2. The mean SVR of untreated specimens was found to be $2.81 \pm$ $0.11 \mathrm{~mm}^{-1}$-this could be regarded as the baseline.

\subsection{Effects on elasticity and fracture of scaffold}

In this section the results of the effects of $p_{W}$ and $t$ on the mechanical properties of the scaffold were presented for the main effects (Fig. 7) and the individual (interaction) effects (Fig. 8). Here, the main effects described the magnitude of the mechanical property at each level of $p_{\mathrm{W}}$ (averaged over the variation due to $t$ ) and at each level of $t$ (averaged over the variations due to $p_{\mathrm{W}}$ ). The individual effects described the variation in the magnitude of the mechanical property in the presence of varying $t$, at each level of $p_{\mathrm{W}}$, and vice versa for $p_{\mathrm{W}}$ at each level of $t$. For details of the respective mechanical properties, see Table 2.

With regard to the main effects of the respective $p_{\mathrm{W}}$ and $t$ on $E$, the $P$ values, i.e., 0.2922 and 0.4266 , were both greater than the alpha level, showing that there was no evidence that both factors affect $E$. The $P$ value for the effects arising from the interaction of $p_{\mathrm{W}}$ and $t(P=0.0654)$ was also greater than the alpha level, showing that there was 
Table 2 Summary of results PLGA/PVA scaffolds from compression testing of

\begin{tabular}{llllllll}
\hline$p_{\mathrm{W}}(\%)$ & $t \mathrm{~min})$ & $U_{0}(\mathrm{~kJ})$ & $\mathrm{SVR}\left(\mathrm{mm}^{-1}\right)$ & $E(\mathrm{MPa})$ & $\sigma_{\mathrm{U}}(\mathrm{MPa})$ & $\varepsilon_{\mathrm{U}}$ & $u_{\mathrm{F}} \times 10^{3}\left(\mathrm{~kJ} / \mathrm{m}^{3}\right)$ \\
\hline Untreated & - & - & $2.81 \pm 0.11$ & $171.9 \pm 53.0$ & $22.3 \pm 5.8$ & $0.131 \pm 0.009$ & $1.45 \pm 0.32$ \\
0 & 5 & 0 & $2.74 \pm 0.24$ & $335.0 \pm 78.9$ & $36.4 \pm 12.8$ & $0.108 \pm 0.021$ & $1.61 \pm 0.91$ \\
0 & 15 & 0 & $2.86 \pm 0.20$ & $285.2 \pm 47.8$ & $34.9 \pm 7.7$ & $0.122 \pm 0.015$ & $1.69 \pm 0.51$ \\
0 & 30 & 0 & $2.83 \pm 0.15$ & $231.3 \pm 62.0$ & $32.6 \pm 13.7$ & $0.137 \pm 0.032$ & $1.83 \pm 1.09$ \\
20 & 5 & 6.6 & $2.71 \pm 0.24$ & $304.6 \pm 71.6$ & $35.2 \pm 7.9$ & $0.117 \pm 0.014$ & $1.54 \pm 0.36$ \\
20 & 15 & 19.8 & $2.59 \pm 0.11$ & $287.7 \pm 18.4$ & $43.3 \pm 5.7$ & $0.151 \pm 0.020$ & $2.74 \pm 0.83$ \\
20 & 30 & 39.6 & $2.82 \pm 0.14$ & $341.3 \pm 13.9$ & $58.4 \pm 4.0$ & $0.171 \pm 0.015$ & $4.33 \pm 0.70$ \\
40 & 5 & 13.2 & $2.71 \pm 0.09$ & $284.3 \pm 59.5$ & $31.6 \pm 11.0$ & $0.110 \pm 0.021$ & $1.36 \pm 0.68$ \\
40 & 15 & 39.6 & $2.94 \pm 0.18$ & $278.7 \pm 47.6$ & $31.2 \pm 6.6$ & $0.112 \pm 0.013$ & $1.38 \pm 0.42$ \\
40 & 30 & 79.2 & $3.19 \pm 0.23$ & $286.6 \pm 57.7$ & $30.3 \pm 6.9$ & $0.106 \pm 0.013$ & $1.28 \pm 0.38$ \\
\hline
\end{tabular}

Fig. 7 Main effects plots of the mechanical properties of PLGA/ PVA scaffold with respect to sonication power $\left(p_{\mathrm{W}}\right)$, and soaking duration $(t)$. A, B Stiffness, E. C, D Fracture strength, $\sigma_{\mathrm{U}} . \mathbf{E}, \mathbf{F}$ Strain at fracture, $\varepsilon_{\mathrm{U}}$. G, $\mathbf{H}$ Fracture toughness, $u_{\mathrm{F}}$. Note that the value of the respective bars on each graph represented the average (plus-minus standard deviation of sample) of all the levels at each $p_{\mathrm{W}}$ or at each $t$
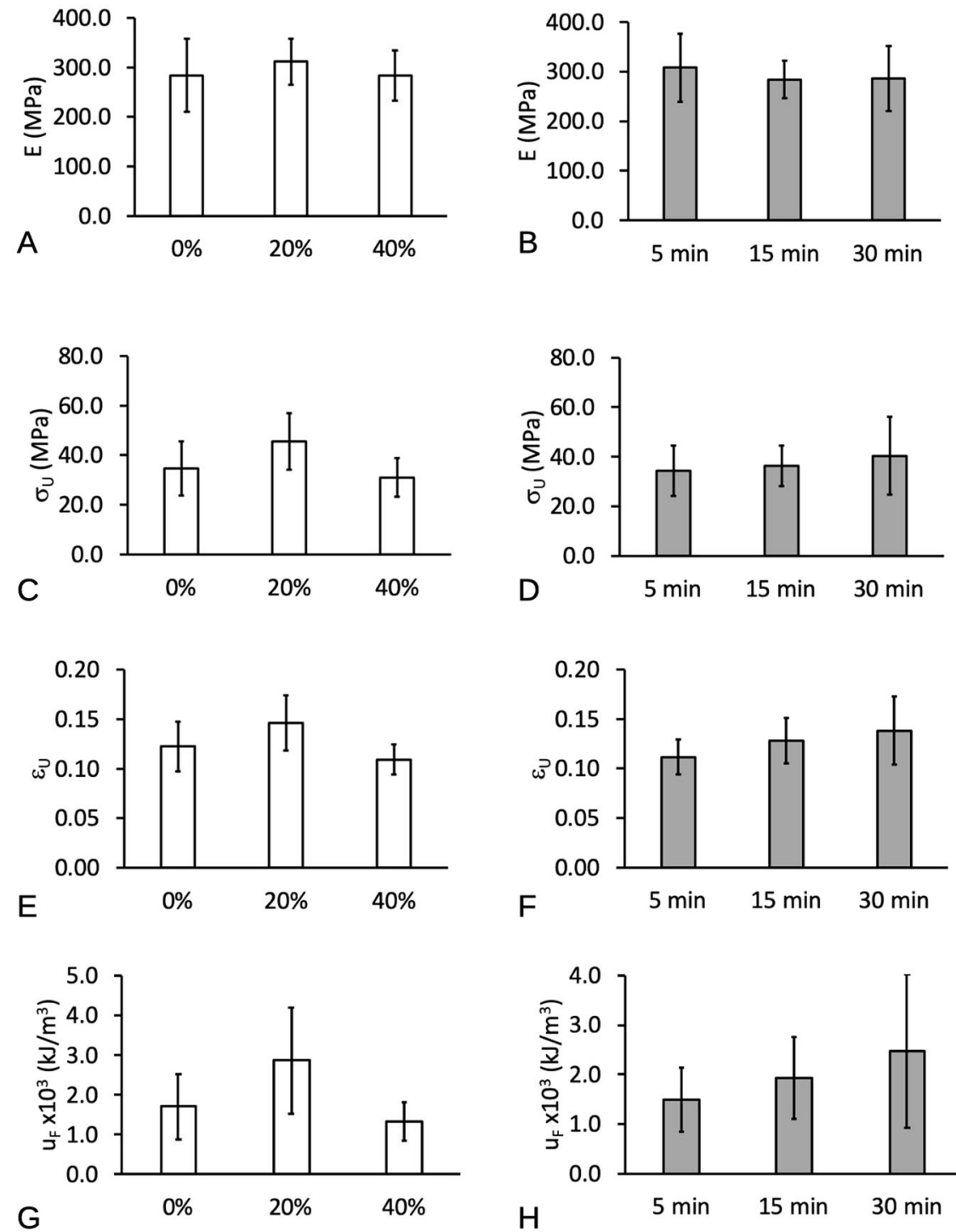

no evidence for an interaction between the factors. Thus, the main effects may be interpreted independently of one another: sonication power does not affect stiffness as does only soaking duration. Consequently, the main effects plots showed no appreciable variation of $E$ with respect to $p_{\mathrm{W}}$ (Fig. 7A) and $t$ (Fig. 7B).

With regard to the main effects of the respective $p_{\mathrm{W}}$ and $t$ on $\sigma_{\mathrm{U}}$, the $P$ value $\left(2.32 \times 10^{-4}\right)$ for $p_{\mathrm{W}}$ was very small 
Fig. 8 Interaction plots of the mechanical properties of PLGA/ PVA scaffold with respect to sonication power $\left(p_{\mathrm{W}}\right)$, and soaking duration $(t)$. A, B Stiffness, E. C, D Fracture strength, $\sigma_{\mathrm{U}}$. E, F Strain at fracture, $\varepsilon_{\mathrm{U}}$. G, $\mathbf{H}$ Fracture toughness, $u_{\mathrm{F}}$
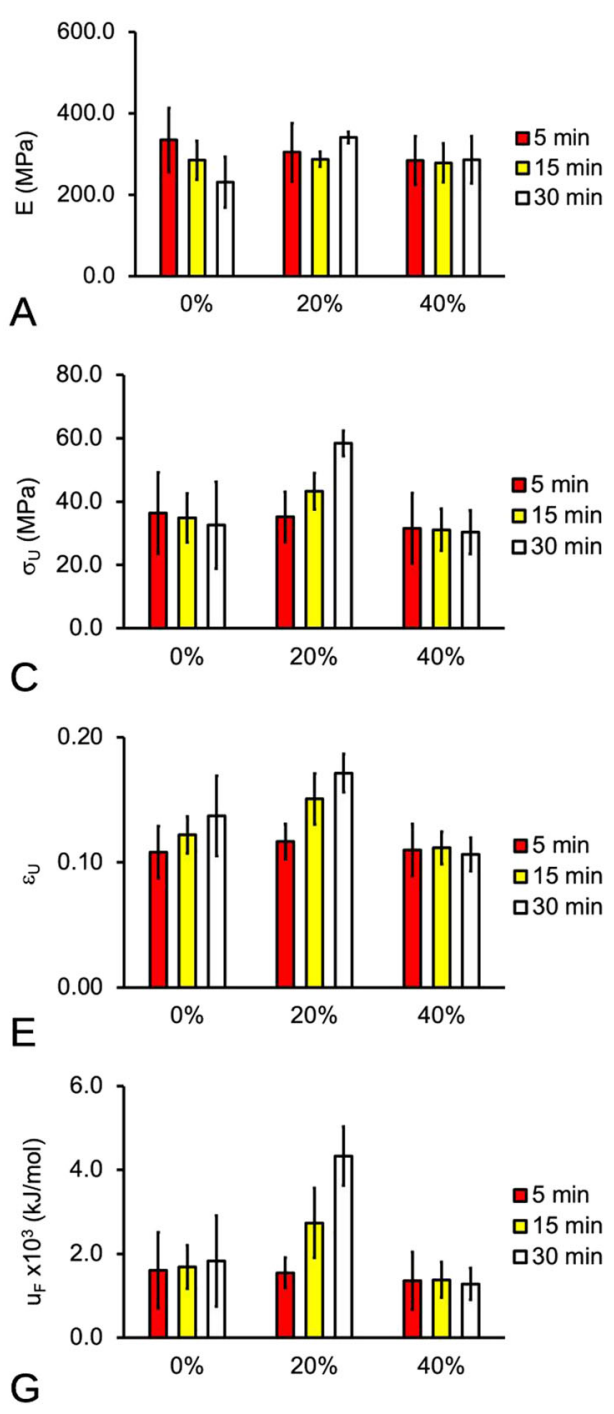
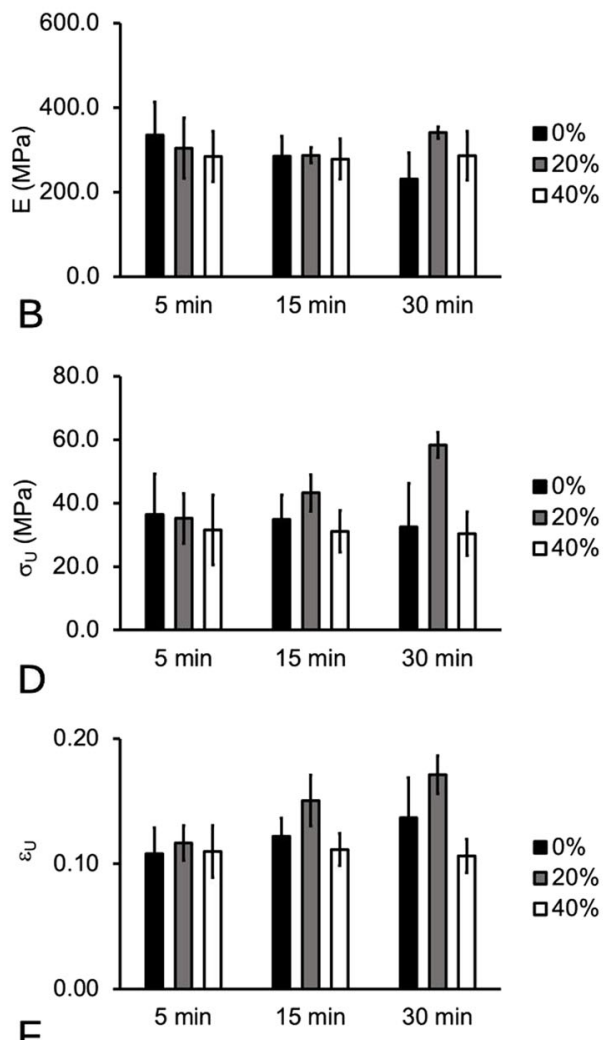

$\mathrm{F}$

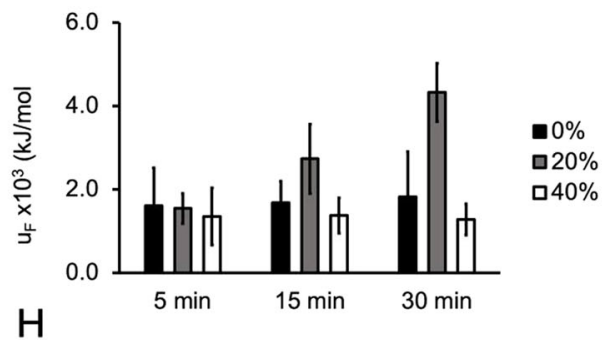

showing that there was very strong evidence that sonication power affected $\sigma_{\mathrm{U}}$. On the other hand, the $P$ value $(=0.194)$ for $t$ was greater than the alpha level, showing that there was no evidence that soaking duration affects $\sigma_{\mathrm{U}}$. However, the $P$ value $(=0.016)$ for the interaction was smaller than the alpha level, showing that there was evidence for an interaction between the factors. Since interaction was significant, the nonsignificant main effects of $t$ in the presence of interaction might well be a result of masking and this lends to the need to observe the influence of $t$ at the fixed levels of $p_{\mathrm{W}}$. As shown in Fig. 8C, with regard to $p_{\mathrm{W}}=0$ and $40 \%$, one-way ANOVA (two-tailed test) revealed that the $P$ values for $t$ were both greater than the alpha level, showing that there was no evidence that the soaking duration affects $\sigma_{\mathrm{U}}$ at these values of $\mathrm{p}_{\mathrm{W}}$. However, with regard to $p_{\mathrm{W}}=$ $20 \%$, the $P$ value $\left(=2.05 \times 10^{-4}\right)$ for $t$ was very small compared to the alpha level, showing that there was evidence that soaking duration affects $\sigma_{\mathrm{U}}$ at this sonication power. In conclusion, with regard to $\sigma_{\mathrm{U}}$ the main effects of $t$ and $p_{\mathrm{W}}$ may not be interpreted independently of one another: there is very strong evidence of sonication power having an effect on $\sigma_{\mathrm{U}}$ in general but this may be modified by the soaking duration. From the interaction plot of Fig. $8 \mathrm{D}$ and one-way ANOVA (two-tailed test), it was found that increasing $p_{\mathrm{W}}$ (at $t=15 \mathrm{~min}$, and $30 \mathrm{~min}$ ) resulted in $\sigma_{\mathrm{U}}$ peaking at $p_{\mathrm{W}}=20 \%$ but more importantly the $t=30 \mathrm{~min}$ yielded the higher magnitude of $\sigma_{\mathrm{U}}$. However, further increase in $p_{\mathrm{W}}$ resulted in a decrease in the $\sigma_{\mathrm{U}}$. Similarly, the interaction plot of Fig. 8C showed that increasing $t$ at only $p_{\mathrm{W}}=20 \%$ resulted in increase in $\sigma_{\mathrm{U}}$. In particular, $\sigma_{\mathrm{U}}$ peaked at $p_{\mathrm{W}}=20 \%$. There was no appreciable change in $\sigma_{\mathrm{U}}$ with increasing $t$ at $p_{\mathrm{W}}=0$ and $40 \%$.

With regard to the main effects of the respective $p_{\mathrm{W}}$ and $t$ on $\varepsilon_{\mathrm{U}}$, the $P$ values, i.e., $2.47 \times 10^{-5}$ and $1.95 \times 10^{-3}$, were both very small, showing that there was very strong evidence that both factors affect $\varepsilon_{\mathrm{U}}$. The $P$ value $(=0.0317)$ for the interaction was smaller than 0.05 , showing that there was evidence for an interaction between the factors. 


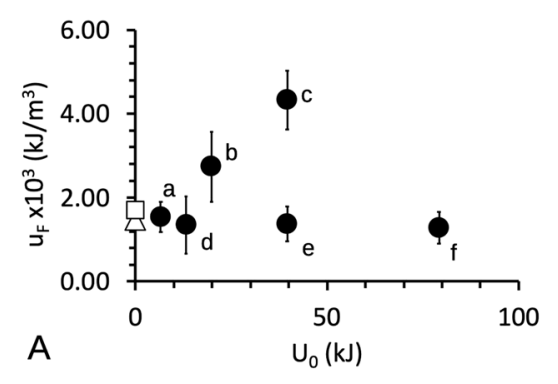

Fig. 9 Predictions of the sonication energy absorbed by the PLGA and PVA in the scaffold. Graphs of (A) mean scaffold fracture toughness $\left(\mathrm{u}_{\mathrm{F}}\right),\left(\right.$ B) predicted strain energy density $\left(\mathrm{u}_{\mathrm{D}}\right)$ absorbed by the scaffold to dislodge PVA, and (C) predicted energy per mole $\left(\mathrm{UM}_{\mathrm{o}} / \mathrm{m}\right)$ imparted to the PVA and PLGA polymers, versus the energy generated by the ultrasonic machine at source, $U_{0}$. The values of $u_{\mathrm{F}}$ were derived from Table 2; the error bars represent standard deviation. In (A), the two data points (unshaded circle $\square$ and diamond $\Delta$ ) at $U_{0}=0$

The main effects may not be interpreted independently of one another: there is very strong evidence of sonication power having an effect on $\varepsilon_{\mathrm{U}}$ in general but this may be modified by the extent of the soaking duration. From the interaction plot of Fig. 8F and one-way ANOVA (two-tailed test), it was found that increasing $p_{\mathrm{W}}$ (at $t=15 \mathrm{~min}$, and $30 \mathrm{~min}$ ) resulted in $\varepsilon_{\mathrm{U}}$ peaking at $p_{\mathrm{W}}=20 \%$ but more importantly the $t=30 \mathrm{~min}$ yielded the higher magnitude of $\varepsilon_{\mathrm{U}}$. However, further increase in $p_{\mathrm{W}}$ resulted in a decrease in the $\varepsilon_{\mathrm{U}}$. Similarly, the interaction plot of Fig. 8E showed that increasing $t$ at only $p_{\mathrm{W}}=20 \%$ resulted in increase in $\varepsilon_{\mathrm{U}}$. In particular, $\varepsilon_{\mathrm{U}}$ peaked at $p_{\mathrm{W}}=20 \%$. There was no appreciable change in $\varepsilon_{\mathrm{U}}$ with increasing $t$ at $p_{\mathrm{W}}=0$ (albeit a trending increase in the mean value) and $40 \%$. As a mean for comparing with the baseline, the mean $\varepsilon_{\mathrm{U}}$ of untreated specimens was found to be $0.131 \pm 0.009 \mathrm{MPa}$.

Finally, with regard to the main effects of the respective $p_{\mathrm{W}}$ and $t$ on $u_{\mathrm{F}}$, the $P$ values, i.e., $1.58 \times 10^{-6}$ and $2.01 \times 10^{-3}$, were both smaller than the alpha level, showing that there was very strong evidence that both factors affected $u_{\mathrm{F}}$. The $P$ value $\left(=5.12 \times 10^{-4}\right)$ for the interaction was smaller than the alpha level, showing that there was evidence for an interaction between the factors. The main effects may not be interpreted independently of one another: there was very strong evidence of $p_{\mathrm{W}}$ having an effect on $u_{\mathrm{F}}$ in general, but this may be modified by the $t$ as shown in Fig. 8. From the interaction plot of Fig. 8H and one-way ANOVA (two-tailed test), it was found that increasing $\mathrm{p}_{\mathrm{W}}$ (at $t=15 \mathrm{~min}$, and $30 \mathrm{~min}$ ) resulted

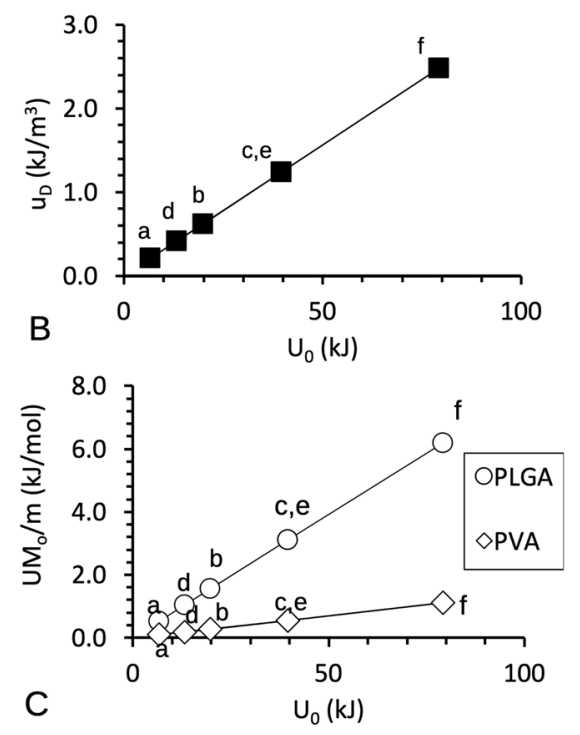

represent the mean values of the respective untreated scaffold and scaffold treated to soaking only. The letters a, b, and c represent the respective level of $\left(p_{\mathrm{W}}, t\right):(20 \%, 5 \mathrm{~min}),(20 \%, 15 \mathrm{~min}),(20 \%$, $30 \mathrm{~min}) ; \mathrm{d}, \mathrm{e}$, and $\mathrm{f}$ represent the respective $(40 \%, 5 \mathrm{~min}),(40 \%$, $15 \mathrm{~min}),(40 \%, 30 \mathrm{~min})$. Symbols $U, M_{\mathrm{o}}$, and $m$ represent the bulk energy imparted to the scaffold, the molar mass of the polymer and mass of the polymer, respectively

in $u_{\mathrm{F}}$ peaking at $p_{\mathrm{W}}=20 \%$ but the $t=30$ min yielded the higher magnitude of $u_{\mathrm{F}}$. However, further increase in $p_{\mathrm{W}}$ resulted in a decrease in the $\sigma_{\mathrm{U}}$. The interaction plot of Fig. $8 \mathrm{G}$ showed that increasing $t$ at only $p_{\mathrm{W}}=20 \%$ resulted in increase in $u_{\mathrm{F}}$. In particular, $u_{\mathrm{F}}$ peaked at $p_{\mathrm{W}}=20 \%$. There was no appreciable change in $u_{\mathrm{F}}$ with increasing $t$ at $p_{\mathrm{W}}=0$ and $40 \%$.

Altogether, the findings from compression testing suggested that $20 \%$ sonication power and 30 min soaking time were the optimal conditions resulting in the highest $\sigma_{\mathrm{U}}, \varepsilon_{\mathrm{U}}$, and $u_{\mathrm{F}}$.

\subsection{Mechanistic analysis of effects of sonication on PLGA and PVA}

The intent of this section is to provide a mechanistic analysis to establish simple order-of-magnitude estimates of the sonication energy absorbed by the PLGA and PVA in the scaffold from molecular to bulk level, to help gain insights into the sensitivity of the $u_{\mathrm{F}}$ to $p_{\mathrm{W}}$, and $t$.

We begin by inspecting the $u_{\mathrm{F}}$ at the respective level of $U_{0}$ generated by the ultrasonic device. Figure $9 \mathrm{~A}$ shows a graph of $u_{\mathrm{F}}$ versus $U_{0}$ to illustrate the effect of sonication at bulk level. Each point $\left(U_{0}, u_{\mathrm{F}}\right)$ corresponded to the respective treatment specified by $p_{\mathrm{W}}$ and $t$, where $U_{0}$ was computed using Eq. (1). For comparison, data points (at $U_{0}=0$ ) of the mean value of $u_{\mathrm{F}}$ of untreated scaffold and scaffolds soaked in the solvent mixture in the absence of sonication have been added to the plot. In the absence of 
sonication, a moderate increase in the $u_{\mathrm{F}}$ of the treated scaffold (as compared to untreated scaffolds) was observed. This indicated that soaking had a moderate influence in enhancing the stiffness of the scaffold. At low $\mathrm{p}_{\mathrm{W}}$, a linear increase in the $u_{\mathrm{F}}$ with increasing $U_{0}$ (i.e., by varying the $t$ ) was observed. This indicated that sonication could result in further enhancement to the $u_{\mathrm{F}}$ at lower $p_{\mathrm{W}}$. However, at high $p_{\mathrm{W}}$, there was no appreciable trending increase or decrease in the $u_{\mathrm{F}}$ with increasing $U_{0}$ (i.e., by varying the $t$ ). This indicated that sonication had no appreciable influence on the $u_{\mathrm{F}}$ at higher $p_{\mathrm{W}}$.

To gain a better understanding of the influence of $p_{\mathrm{W}}$ on $u_{\mathrm{F}}$, we present an argument for establishing order of magnitude estimates of the bulk energy absorbed by the scaffold. To begin, we replaced $I$ by $U$ and $I_{0}$ by $U_{0}$. For definiteness, the bulk energy imparted to the scaffold, $U$, was found using Eqs. (2) and (3), by setting the $\mu$ equal to that of ethanol ( $=0.0018318$ Pa.s, room temperature), $\gamma=$ $789.30 \mathrm{~kg} / \mathrm{m}^{3}$ (ethanol), $x=120 \mathrm{~mm}$ (mid-point of the tub), $f=40 \mathrm{kHz}$, and $G=0.016$. In forming the scaffold, the molar mass $\left(M_{\mathrm{o}}\right)$ of the PLGA and PVA was estimated at 5 and $0.09 \mathrm{~kg} / \mathrm{mol}$, respectively. For simplicity, the mass $(m)$ of PLGA was assumed to be comparable to that of PVA, valid to order of magnitude (i.e., $10 \mathrm{mg}$ or $10^{-5} \mathrm{~kg}$ ). The strain energy density absorbed by the scaffold, $u_{\mathrm{D}}$, was identified with the ratio of $U$ to the volume of the scaffold. For the purpose of computing $u_{\mathrm{D}}$, we estimated the volume of the scaffold as equal to $50 \mathrm{~mm}^{3}$. Figure $9 \mathrm{~B}$ shows a graph of the predicted $u_{\mathrm{D}}$ versus $U_{0}$ to illustrate the predicted energy absorbed by the scaffold. As we might have expected, the $u_{\mathrm{D}}$ increased linearly with increase in $U_{0}$. The predicted values of $u_{\mathrm{D}}$ - estimated to order of magnitude of $10^{3} \mathrm{~kJ} / \mathrm{m}^{3}$ - were much smaller than the $u_{\mathrm{F}}$ (Fig. 9A). This indicated that the energy that was absorbed by the scaffold was not sufficient to cause the scaffolds to rupture. However, it could have consequential result in dislodging the PVA residuals from the PLGA network.

Let us examine more fundamentally at the molecular level why this should be so. The energy per mole imparted to the respective polymer may be identified with $\mathrm{UM}_{\mathrm{o}} / \mathrm{m}$ and is determined as follows. In our simplified model, at a given $t$, the wave propagated through area of order of magnitude of the scaffold surface area. Figure 9C shows a graph of $U M_{\mathrm{o}} / m$ imparted to the PVA and PLGA versus $U_{0}$, to illustrate the effects of sonication at the molecular level. The predictions revealed that increasing $U_{0}$ resulted in a linear increase in the $U M_{\mathrm{O}} / m$ imparted to the PLGA and PVA respectively. Numerically, the predicted value of the $U M_{\mathrm{o}} / m$ ranged 0.1 to $6.0 \mathrm{~kJ} / \mathrm{mol}$. Gutowski highlighted that the energy to form interatomic bonds such as covalent bonds ranges $63-920 \mathrm{~kJ} /$ mol-derived from basic classical principles of electrostatics and electrodynamics that underpin assumptions about the structure and distribution of the molecules and atoms [23].
Gutowski also highlighted that the energy for van der Waals interactions ranges $4-42 \mathrm{~kJ} / \mathrm{mol}$ [23]. In our simplified model, the predicted values of $U M_{\mathrm{o}} / m$ were much smaller than the energy associated with covalent bonds but were of the same order of magnitude for van der Waals interactions. The latter could contribute to the interaction between PVA residuals and the PLGA network. Thus the energy imparted to the respectively polymer in the scaffold would not be sufficient to cause bond dissociation in the PLGA and PVA molecules but is expected to be able to cause the PVA residuals to be dislodged from the PLGA network.

\section{Discussion}

In this study on a technique of a post-process stage to partially remove the PVA binder in PLGA dental scaffolds, we have investigated the effects of $\mathrm{p}_{\mathrm{W}}$ and $\mathrm{t}$ on the structure and mechanical properties of the PLGA-based scaffold. Our results had enabled us to identify the $p_{\mathrm{W}}$ and $t$ levels that resulted in a scaffold with optimal mechanical properties and structure, as well as a confluence of evidence on the $p_{\mathrm{W}}$ and $t$ central to regulating the amount of PVA present in the scaffold. From FT-IR, it was observed that the amount of PVA decreased with increase in $\mathrm{p}_{\mathrm{W}}$ and $\mathrm{t}$ but this did not completely remove the PVA from the scaffold. From optical microscopy, it was observed that the sonication and prolonged immersion in the solvent resulted in surface unevenness. This was attributed to the shock waves in the form of microscopic jet stream impacting on the scaffold surface (from sonication) and to both processes of dissolution to facilitate PVA removal and the process of emulsification of the PLGA to regain the structure (from the polar-non-polar solvent). The unevenness was least appreciable at $p_{\mathrm{W}}=20 \%(22 \mathrm{~W})$ and $t=30 \mathrm{~min}$. From the SVR analysis, it was found that high $p_{\mathrm{W}}$ and $t$ resulted in higher surface to volume ratio, which could be attributed to the combined effects of removing PVA (albeit partially) and shrinkage during re-bonding. Results from mechanical testing suggested that there exists a critical value for the respective $p_{\mathrm{W}}$ and $t$ beyond which the scaffold experiences a decrease in fracture strength, fracture strain and fracture toughness. This was found to be $p_{\mathrm{W}}=20 \%$ and $t=30 \mathrm{~min}$, which corroborated the findings derived from optical microscopy. The enhanced mechanical properties could be attributed to the overall shrinkage in the scaffold with corresponding reduction in porosity. The mechanistic analysis predicted that the sonication energy imparted to the scaffold was sufficient to disrupt the van Der Waals bonding between the agglomerates of PLGA powder but not high enough to disrupt the covalent bonding within the PLGA. The confluence of evidence revealed an optimal state corresponding to $p_{\mathrm{W}}=20 \%$ and $t=$ $30 \mathrm{~min}$ whereby the scaffold exhibited enhanced mechanical 
properties, surface to volume ratio and minimal surface damage in the presence of a reduced PVA concentration.

The mechanical characterization study revealed that reducing the PVA concentration resulted in enhanced mechanical properties which was in good agreement with finding from previous studies. Mechanical characterization of melt-molded scaffolds had revealed that increasing PVA concentration in the PLGA-based scaffold could lead to decreasing elastic modulus [8] and maximum force of rupture [8]. PLGA scaffolds made from wet-spun hollow fiber with porous walls also exhibited decreasing elastic modulus, maximum force of rupture as well as work of fracture with increasing PVA concentration [10]. Altogether these findings are consistent with the rule-of-mixture model for a two-phase composite (Section 2.2), whereby increasing the phase characterized by lower stiffness and strength would result in decreasing the overall stiffness [24] and strength [25] of the composite.

As pointed out in Section 2.1, sonication is known to produce heat that could result in high temperatures at the local regions around the target, i.e., the scaffolds. If the temperatures were sufficiently high, namely $160^{\circ} \mathrm{C}$ and above, yellowish tint could appear on the scaffold [15]. This is because when the PVA is heated, it produces polyenes sequences $(-\mathrm{CH}=\mathrm{CH}-)_{\mathrm{n}}$ where the molecules form alternate single and double bonds with a compound group consisting of a carbonyl center and hydrogen $[16,18]$. Yet, we did not observe any yellowish tint on the sonicated scaffolds, implying that the local temperatures were not high enough to cause this to happen. To lend support to this conclusion, in the following text, we present an argument for the order of magnitude estimate of the temperature of the surface of the scaffold $\left(T_{\mathrm{s}}\right)$. According to Taurozzi et al. the ultrasonic waves could result in bubbles (cavitation process) which when collapsed could generate shock waves, producing liquid jet streaming at speed $(v)$ of order of magnitude estimate of $100 \mathrm{~m} / \mathrm{s}$. The heat transfer problem may be evaluated to order of magnitude by noting that the $p_{\mathrm{W}}$ is identified with the rate of heat change, $\mathrm{d} Q / \mathrm{d} t$, where

$\mathrm{dQ} / \mathrm{dt}=\mathrm{hA}\left(T_{s}-T_{\text {bath }}\right)$

where $A$ is the surface area of a side face of the scaffold (Section 2.4), $T_{\mathrm{s}}$ and $T_{\text {bath }}$ are the temperatures at the scaffold surface and in the bath, respectively, and $\mathrm{h}$ is the heat transfer coefficient by convection. We may estimate $h$ from

$h=\mathrm{Nu} \cdot k / D_{\mathrm{o}}$

where $D_{\mathrm{o}}$ is a characteristic dimension of the target, $k$ the thermal conductivity of the solvent, and $\mathrm{Nu}$ (the Nusselt number) is given by

$\mathrm{Nu}=C\left(\operatorname{Re}^{m} \operatorname{Pr}^{1 / 3}\right)$

where $\operatorname{Pr}$ is Prandtl's number, $C$ and $m$ are constants depending on the value of $\mathrm{Re}$, the Reynold number, given by

$\operatorname{Re}=\rho \nu L / \mu$

where $\rho$ is density of the fluid, $v$ the speed of the fluid, $\mu$ the dynamic viscosity of the fluid, and $L$ (the dimensional parameter of the Re). At $T_{\text {bath }}=25^{\circ} \mathrm{C}$, with practical values accorded to the properties of the individual components (ethanol, acetone), namely $\rho=\left(785.3 \mathrm{~kg} / \mathrm{m}^{3}, 784.0 \mathrm{~kg} / \mathrm{m}^{3}\right)$; $k=(0.167 \mathrm{~W} / \mathrm{m} . \mathrm{K}, \quad 0.180 \mathrm{~W} / \mathrm{m} . \mathrm{K}) ; \mu=(0.001074 \mathrm{~kg} / \mathrm{m} . \mathrm{s}$, $0.000309 \mathrm{~kg} / \mathrm{m} . \mathrm{s})$ and $\mathrm{Pr}=(18.05,4.50)$, it seems reasonable to identify $D_{0}$ with the thickness of the scaffold wall, i.e., $D_{\mathrm{o}} \sim D_{\mathrm{OD}}-D_{\mathrm{ID}}$, and $L$ with $L_{0}$, where the values of $D_{\mathrm{OD}}, D_{\mathrm{ID}}$, and $L_{0}$ (see Section 2.4) were averaged from all the specimens used in the study, for simplicity. Substituting the values of $\rho, v, L$, and $m$ into Eq. (8) to determine Re, at around the scaffold we predicted that the flow attributed to the respective ethanol $\left(\operatorname{Re}=5 \times 10^{5}\right)$ and acetone $(\operatorname{Re}=$ $19 \times 10^{5}$ ) could be turbulent. Noting that $C=0.027$ and $m=0.805$, substituting the $\operatorname{Re}$ and $\operatorname{Pr}$ values into Eq. (7), we obtained the corresponding values of $\mathrm{Nu}=3 \times 10^{3}$ (ethanol) and $5 \times 10^{3}$ (acetone). Next, substituting the values of $\mathrm{Nu}, k$, and $D_{\mathrm{o}}$ into Eq. (6), we obtained the corresponding values of $h=3 \times 10^{5} \mathrm{~W} / \mathrm{m}^{2} \mathrm{~K}$ (ethanol) and $6 \times 10^{5} \mathrm{~W} / \mathrm{m}^{2} \mathrm{~K}$ (acetone). Finally, substituting the appropriate values for $\mathrm{d} Q / \mathrm{d} t\left(=p_{\mathrm{W}}\right), h, A_{\mathrm{s}}$, and $T_{\text {bath }}$ into Eq. (5), we predicted that at the scaffold surface, the ethanol component in the solvent could contribute to raising the temperature from $T_{\text {bath }}$ to $T_{\mathrm{s}}=36^{\circ} \mathrm{C}(22 \mathrm{~W})$ and $46^{\circ} \mathrm{C}$ $(44 \mathrm{~W})$. On the other hand, the presence of acetone in the solvent could result in $T_{\mathrm{s}}=31{ }^{\circ} \mathrm{C}(22 \mathrm{~W})$ and $36{ }^{\circ} \mathrm{C}(44 \mathrm{~W})$. Of note, the $T_{\mathrm{s}} \mathrm{s}$ of the respective ethanol and acetone were smaller than their boiling points, indicating that no boiling had taken place (in reality, only evaporation was observed). More importantly, since these temperatures were lower than the critical temperature $\left(160^{\circ} \mathrm{C}\right)$ for thermal degradation (i.e. resulting in the production of polyene (yellow) residue [16-18]) thus yellowing was not observed during the sonication process. For further details about the calculations and the values used for $\rho, k, \mu$, and $\operatorname{Pr}$, see Supplementary Information.

This technique to enable partial removal of the PVA in the PLGA-based scaffold is promising as it could mitigate several problematic issues related to the PLGA scaffold down the line, such as thermal degradation during sterilization and undue prolong/variability in the biodegradability. There have 
been many studies on the development and application of PLGA bioscaffolds for dental socket preservation, with and without a binder for the forming process. The use of PVA in the processing of 3D printed PLGA scaffolds is established. However, the process encounters several hurdles when it is translated into commercial production due to regulatory requirements. Moving forward, there are two issues to be addressed before the sonication process can be fully incorporated into the manufacturing process. First, although the presence of PVA in PLGA scaffolds can facilitate the bone regeneration by enhancing the scaffold hydrophilicity (i.e., increasing the concentration of PVA increases hydrophilicity) for cell adhesion and growth on the scaffold [8], the possibility of toxicity arising from changes to the polymers during sonication and solvent immersion may not be ruled out. This would require carrying out cell viability test, e.g., to assess for cytotoxicity to osteoblasts by observing for proliferation. This has been identified as an area for further study. The second issue concerns the sterilization stage. Sterilization could involve one or more of the following, namely heat, high pressure and radiation [26], which could result in thermal degradation of the PVA. As pointed out earlier with regard to previous studies, under heat treatment at high temperatures, decolorization (i.e., yellowing) was observed due to the presence of polyene residues; irradiating the scaffolds could result in radiation-induced cross-links. Clearly reducing the presence of PVA would minimize this effect - and in turn mitigate the effects on the mechanical properties-which was what the current study aimed to establish. An investigation into how sterilization affects the mechanical properties of the scaffolds that were treated to the sonication process was out of the scope of this study. However, this had also been identified as an area for future study.

\section{Conclusions}

We have proposed a post-processing technique to partially remove the PVA in the PLGA/PVA scaffold by sonicating the PLGA/PVA scaffold in the presence of a solvent mixture possessing polar-nonpolar properties. The effects of $p_{\mathrm{W}}$ and $t$ on the structure (SVR) and mechanical properties $(E$, $\sigma_{\mathrm{U}}, \varepsilon_{\mathrm{U}}$, and $u_{\mathrm{F}}$ ) of PLGA/PVA scaffolds immersed in the ethanol/acetone as the polar-nonpolar solvent mixture were investigated. The findings from this study are summarized as follows.

- The optimal state of the scaffold, associated with the highest $\sigma_{\mathrm{U}}, \varepsilon_{\mathrm{U}}$, and $u_{\mathrm{F}}$, occurred at $p_{\mathrm{W}}=20 \%$ and $t=$ $30 \mathrm{~min}$, which corroborated the finding of minimal surface unevenness as seen from optical microscopy.
- FT-IR showed that the PVA was not completely removed from the PLGA scaffolds over the range of soaking duration and sonication power investigated.

- A mechanistic analysis of the energy imparted to the respectively polymer in the scaffold indicated that the energy would not be sufficient to cause bond dissociation in the PLGA and PVA molecules but is expected to be able to cause the PVA residuals to be dislodged from the PLGA network.

This simple technique is promising as it can help to regulate the amount of PVA, i.e., partially removing PVA, that is present in the PLGA scaffold and to optimize the scaffold toward achieving enhanced $\sigma_{\mathrm{U}}, \varepsilon_{\mathrm{U}}$, and $u_{\mathrm{F}}$ within the regulatory controls.

\section{Data availability}

The data that support the findings of this study are available from the corresponding author, KLG, upon reasonable request.

Acknowledgements We thank Dr Ronnie Teo from SIMTECH (A*STAR) Singapore for his help with the FT-IR study. We also thank Newcastle University in Singapore for funding the consumables used in the research and for appointing MC as a visiting scholar. We express our gratitude to Professor David Hukins (University of Birmingham) for his advice during the preparation of the manuscript. We are deeply grateful to Dr Steven Tay (Singapore Institute of Technology) for his guidance on the fundamentals of heat transfer. We found this topic to be very useful and this led to a detailed analysis of the effects of local heating at the PLGA scaffolds during the sonication process. Finally, we are grateful to an anonymous reviewer for many helpful suggestions, particularly on the microscopic examination and FT-IR analysis.

Author contributions MC conceived of the presented idea. RNVCV contributed to the design of the experiments and carried out the experiments. KLG developed the theory and performed the computations. RNVCV, MC, KW, and KLG contributed to the analysis of the results and to the writing of the paper.

Funding Newcastle University in Singapore contributed funds to purchase the consumables used in the research.

\section{Compliance with ethical standards}

Conflict of interest The authors declare no competing interests.

Publisher's note Springer Nature remains neutral with regard to jurisdictional claims in published maps and institutional affiliations.

Open Access This article is licensed under a Creative Commons Attribution 4.0 International License, which permits use, sharing, adaptation, distribution and reproduction in any medium or format, as long as you give appropriate credit to the original author(s) and the source, provide a link to the Creative Commons license, and indicate if changes were made. The images or other third party material in this 
article are included in the article's Creative Commons license, unless indicated otherwise in a credit line to the material. If material is not included in the article's Creative Commons license and your intended use is not permitted by statutory regulation or exceeds the permitted use, you will need to obtain permission directly from the copyright holder. To view a copy of this license, visit http://creativecommons. org/licenses/by/4.0/.

\section{References}

1. Tan WL, Wong TL, Wong MC, Lang NP. A systematic review of post-extractional alveolar hard and soft tissue dimensional changes in humans. Clin Oral Implants Res. 2012;23:1-21.

2. Horowitz R, Holtzclaw D, Rosen PS. A review on alveolar ridge preservation following tooth extraction. J Evid Based Dent Pract. 2012;12:149-60.

3. Saito H, Shiau HJ, Prasad H, Reynolds MA. Evaluation of a Poly (Lactic-Co-Glycolic) acid-coated beta-tricalcium phosphate bone substitute for alveolar ridge preservation: case series. Clin Adv Periodontics. 2017;7:190-4.

4. Brown A, Zaky S, Ray H Jr., Sfeir C. Porous magnesium/PLGA composite scaffolds for enhanced bone regeneration following tooth extraction. Acta Biomater. 2015;11:543-53.

5. Virlan MJR, Miricescu D, Totan A, Greabu M, Tanase C, Sabliov $\mathrm{CM}$, et al. Current uses of Poly(lactic-co-glycolic acid) in the dental field: a comprehensive review. J Chem. 2015;2015:525832. https://doi.org/10.1155/2015/525832.

6. Yang Y, Ren S, Zhang X, Yu Y, Liu C, Yang J, et al. Safety and efficacy of PLGA(Ag-Fe3O4)-coated dental implants in inhibiting bacteria adherence and osteogenic inducement under a magnetic field. Int J Nanomed. 2018;13:3751-62.

7. Chandrasekaran M, Zhang SX, Tay BY. Method for obtaining graded pore structure in scaffolds for tissues and bone and scaffolds with graded pore structure for tissue and bone, T.R.o.P. Singapore: Agency for Science, Technology and Research; 2005.

8. Oh SH, Kang SG, Kim ES, Cho SH, Lee JH. Fabrication and characterization of hydrophilic poly(lactic-co-glycolic acid)/poly (vinyl alcohol) blend cell scaffolds by melt-molding particulateleaching method. Biomaterials. 2003;24:4011-21.

9. Shirazi SF, Gharehkhani S, Mehrali M, Yarmand H, Metselaar HS, Adib Kadri N, Osman NA. A review on powder-based additive manufacturing for tissue engineering: selective laser sintering and inkjet 3D printing. Sci Technol Adv Mater. 2015;16:033502.

10. Meneghello G, Parker DJ, Ainsworth BJ, Perera SP, Chaudhuri $\mathrm{JB}$, Ellis MJ, et al. Fabrication and characterization of poly(lacticco-glycolic acid)/polyvinyl alcohol blended hollow fibre membranes for tissue engineering applications. J Membr Sci. 2009;344:55-61.

11. Sahoo SK, Panyam J, Prabha S, Labhasetwar V. Residual polyvinyl alcohol associated with poly (D,L-lactide-co- glycolide) nanoparticles affects their physical properties and cellular uptake. J Control Release. 2002;82:105-14.

12. Ajalloueian F, Tavanai H, Hilborn J, Donzel-Gargand O, Leifer K, Wickham A, et al. Emulsion electrospinning as an approach to fabricate PLGA/chitosan nanofibers for biomedical applications. BioMed Res Int. 2014;2014:13.

13. Hecker W, Witthauer D, Staerk A. Validation of dry heat inactivation of bacterial endotoxins. PDA J Pharm Sci Technol. 1994;48:197-204.

14. Moesby L, Hansen EW, Christensen JD, Høyer CH, Juhl GL, Olsen HB. Dry and moist heat sterilisation cannot inactivate pyrogenicity of Gram positive microorganisms. Eur J Pharm Sci. 2005;26:318-23.

15. Phung KV. Non yellowing, thermally stable polyvinyl alcohol. U. S. Patent, 6,046,272, Apr. 4, 2000 Editor; 1998.
16. Holland BJ, Hay JN. The thermal degradation of poly(vinyl alcohol). Polymer. 2001;42:6775-83.

17. Maruyama K, Asakura H. Dichroism analysis of polyenes produced in heat-treated PVA. Polymer. 1990;31:2053-6.

18. Maruyama K, Kuramoto Y, Tanizaki Y. Absorption coefficients of polyenes in heated poly(vinyl alcohol) film and distribution of polyenes formed by its photodegradation. Polymer. 1989;30:1419-24.

19. Bian Y, Colin X, Aressy M. Thermal aging of high tenacity polyvinyl alcohol yarns. Polym Degrad Stability. 2020;179:109277. https://doi.org/10.1016/j.polymdegradstab. 2020.109277.

20. Taurozzi JS, Hackley VA, Wiesner MR. Ultrasonic dispersion of nanoparticles for environmental, health and safety assessment-issues and recommendations. Nanotoxicology. 2010;5:711-729.

21. Grönroos A, Pirkonen P, Heikkinen J, Ihalainen J, Mursunen H, Sekki H. Ultrasonic depolymerization of aqueous polyvinyl alcohol. Ultrason Sonochem. 2001;8:259-64.

22. Peixoto LS, Silva FM, Niemeyer MAL, Espinosa G, Melo PA, Nele M, et al. Synthesis of Poly(Vinyl Alcohol) and/or Poly(Vinyl Acetate) particles with spherical morphology and core-shell structure and its use in vascular embolization. Macromol Symposia. 2006;243:190-9.

23. Gutowski W. Thermodynamics of adhesion, in fundamentals of adhesion. Lee LH, editor. Springer, Boston, MA. 1991. p. 87-135. https://doi.org/10.1007/978-1-4899-2073-7_2.

24. Xie JZ, Hein S, Wang K, Liao K, Goh KL. Influence of hydroxyapatite crystallization temperature and concentration on stress transfer in wet-spun nanohydroxyapatite-chitosan composite fibres. Biomed Mater. 2008;3:2-6.

25. De Silva R, Pasbakhsh P, Qureshi AJ, Gibson AG, Goh KL. Stress transfer and fracture in nanostructured particulatereinforced chitosan biopolymer composites: Influence of interfacial shear stress and particle slenderness. Composite Interfaces. 2014;21:807-18.

26. Holy CE, Cheng C, Davies JE, Shoichet MS. Optimizing the sterilization of PLGA scaffolds for use in tissue engineering. Biomaterials. 2001;22:25-31.

27. Vijayalakshmi S, Mariadoss A.V.A, Ramachandran V, Shalini V, Agilan B, Sangeetha C.C. et al. Polydatin encapsulated Poly [Lactic-co-glycolic acid] nanoformulation counteract the 7,12Dimethylbenz[a] anthracene mediated experimental carcinogenesis through the inhibition of cell proliferation. Antioxidants. 2019;8:375. https://doi.org/10.3390/antiox8090375.

28. Esfandyari-Manesh M, Mostafavi SH, Majidi RF, Koopaei MN, Ravari NS, Amini M, et al. Improved anticancer delivery of paclitaxel by albumin surface modification of PLGA nanoparticles. Daru. 2015;23:28.

29. Pietra RCCdS, Cruz RC, Melo CM, Rodrigues LB, Santos PC, Bretz GPM, et al. Evaluation of polymeric PLGA nanoparticles conjugated to curcumin for use in aPDT. Brazil J Pharm Sci. 2017;53:e16043. https://doi.org/10.1590/s2175-97902017000216043.

30. Dubey RD, Saneja A, Qayum A, Singh A, Mahajan G, Chashoo $\mathrm{G}$, et al. PLGA nanoparticles augmented the anticancer potential of pentacyclic triterpenediol in vivo in mice. RSC Adv. 2016;6:74586-97.

31. Paragkumar NT, Edith D, Six J-L. Surface characteristics of PLA and PLGA films. Appl Surf Sci. 2006;253:2758-64.

32. D'Avila Carvalho Erbetta C. Synthesis and characterization of Poly(D,L-Lactide-co-Glycolide) copolymer. J Biomater Nanobiotechnol. 2012;03:208-25.

33. Liu F, Guo R, Shen M, Wang S, Shi X.Effect of processing variables on the morphology of electrospun Poly[(lactic acid)-co-(glycolicacid)] nanofibers.Macromol Mater Eng.2009;294:666-72.

34. Kharazmi A, Faraji N, Mat Hussin R, Saion E, Yunus WM, Behzad K. Structural, optical, opto-thermal and thermal properties 
of ZnS-PVA nanofluids synthesized through a radiolytic approach. Beilstein J Nanotechnol. 2015;6:529-36.

35. Dilaver M, Yurdakoc K. Fumaric acid cross-linked carboxymethylcellulose/poly(vinyl alcohol) hydrogels. Polym Bull. 2016;73:2661-75.

36. Luo S, Qiao X, Wang QY, Zhang YF, Fu P, Lin ZD, et al. Excellent self-healing and antifogging coatings based on polyvinyl alcohol/hydrolyzed poly(styrene-co-maleic anhydride). J Mater Sci. 2019;54:5961-70.
37. Chen T, Wu Z, Wei W, Xie Y, Wang X, Niu M, et al. Hybrid composites of polyvinyl alcohol (PVA)/Si-Al for improving the properties of ultra-low density fiberboard (ULDF). RSC Adv. 2016;6:20706-12.

38. Parthasarathy V, Selvi J, Senthil Kumar P, Anbarasan R, Mahalakshmi S. Evaluation of mechanical, optical and thermal properties of PVA nanocomposites embedded with $\mathrm{Fe} 2 \mathrm{O} 3$ nanofillers and the investigation of their thermal decomposition characteristics under non-isothermal heating condition. Polym. Bull. 2021;78:2191-2210. https://doi.org/10.1007/s00289-020-03206-3. 